\title{
Impact on women who care for those with schizophrenia
}

\author{
Marcia Scazufca and Elizabeth Kuipers
}

This study examined the impact of caring on women who were primary care-givers to those with schizophrenia. From the 46 women and 21 men carers ascessed for the study, women were considered pitmory care-givers more often than men $183 \% v$. 57\%). Higher lovels of burden among women primary carers were associated with Itving with patients, and more hours in contact with them. Worse perception of patients' social functioning was associated with higher lovels of burden. The findings of the study showed that women primary carers hove particular needs, and services should consider how to provide support for them in their multiple roles, and over longer periods of timo.

Research with carers of people suffering from a severe mental illness has shown quite consistently over the last 40 years that families are affected in several aspects of their lives, and that this may cause distress (Deasy \& Quinn, 1955; Grad \& Sainsbury, 1968; Gibbons et al, 1984; MacCarthy et al, 1989). The expression "burden of care" has been used to describe the impact of the patient's behavioural problems and social disabilities on family life (Platt, 1985). Thurer (1983) highlighted the important role of women as the main carers of patients in the community, and considered "deinstitutionalisation" to be a women's issue. Several studies with carers of severely mentally ill patients did not find any difference between levels of burden and the sex of the carers (Thompson \& Doll, 1982; Biegel et al, 1994; Tessler \& Gamache, 1994). However, a few studies have described some specific aspects of the impact on women carers. Creer \& Wing (1975) found that mothers considered themselves virtually the patients' only social contact. Stevens (1972) reported that middle-aged patients with schizophrenia were frequently dependent on elderly mothers, who reported financial and health problems (anxiety and depression). lack of communication with their children, and the fear about what would happen to their children after their death. Carpentler et al (1992) found that women who were single parents reported more burden than women living with partners.
The objectives of the present study were to examine whether levels of burden of care were associated with various characteristics of women who were carers of patients with schizophrenia. It also aimed to describe which areas of women's lives were more affected, and the relationship between patients' behavioural problems and disabilities in performing everyday tasks, and the burden of care. This study was part of a longitudinal investigation of the relationship between expressed emotion and burden of care in relatives of those with schizophrenia (Scazufca \& Kuipers, 1996).

\section{The study}

Patients admitted in acute crises with a diagnosis of schizophrenia or schizophreniform disorder (DSM-III-R; American Psychiatric Association, 1987) to two hospitals in south London, who were living or were in close contact with relatives (at least once per week) for at least three months before admission, were asked to participate in the study and for permission to interview their relatives. If they consented, their relatives were asked whether they wanted to participate. Relatives were assessed for burden of care, using the section "adverse effect on others" of the Social and Behaviour Assessment Schedule (SBAS; Platt et al, 1980), and items from the Camberwell Family Interview (CFI; Vaughn \& Leff, 1976) concerning the "informants relationship with the patient". Their perceptions of the patients' behavioural problems were assessed using a short version of the Social Behaviour Schedule (SBS; Wykes \& Sturt, 1986; Brewin et al, 1990), and patients' role performance with the Social Role Performance schedule (SRP: Brewin et al, 1987). The period covered for those assessments was the month before the patient's admission to hospital. Sociodemographic characteristics of patients and relatives and illness-related characteristics of patients were recorded. All patients had at least one relative interviewed. When more than one relative was interviewed per patient, the relative who spent more time with the patient and was 
more involved with his/her care was considered the primary care-giver.

\section{Findings}

Sixty-seven relatives (46 women and 21 men) of 50 patients were interviewed. Fifty relatives were considered primary carers, of whom 38 (76\%) were women. Women were considered primary care-givers more often than men $(83 \%$ v. $57 \%$; $\chi^{2}=4.94$, d.f. $=1, P=0.03$ ).

Table 1 shows the characteristics of primary care-givers. Primary carers were predominantly mothers. Twenty-four mothers (73\%) who were primary carers were living with patients, compared with two fathers (29\%) who were primary carers (Fisher's exact two-tailed probability, $P=0.039$ ). Eighteen such mothers (75\%) were not living with partners, whereas the two fathers were.

Thirty-seven patients $(74 \%)$ were men. The mean age of the patients was 26.8 years (s.d. $=6.2$ years, range $17-43$ ). Only five patients (13\%) were working or studying regularly before admission to hospital. Eight patients (21\%) had been admitted to a psychiatric hospital for the first time, $18(47 \%)$ had had 1-3 previous admissions, and $12(32 \%)$ had had more than three previous admissions. The mean length of illness was 5.3 years, ranging from less than 1 to 26 years.

Women primary carers were affected in all areas investigated. The area they reported as having higher levels of burden was effect on relationship', followed by 'effect on household affairs', 'effect on employment', 'effect in finances', and 'effect on social life'.

Table 1. Characteristics of the relatives

\begin{tabular}{lll}
\hline & $\begin{array}{l}\text { Women } \\
(n=38)\end{array}$ & $\begin{array}{l}\text { Men } \\
(n=12)\end{array}$ \\
\hline $\begin{array}{lll}\text { Age (years) } \\
\text { mean (s.d.) }\end{array}$ & $50.95(11.54)$ & $45.41(16.29)$ \\
range & $26-77$ & $22-63$ \\
Relationship to patient & & \\
parent & $33(86.8 \%)$ & $7(58.3 \%)$ \\
sibling & $5(13.2 \%)$ & $4(33.3 \%)$ \\
partner & - & $1(8.3 \%)$ \\
Employment status (yes) & $21(55.3 \%)$ & $5(41.7 \%)$ \\
Uving with partner' & $11(28.9 \%)$ & $7(63.6 \%)$ \\
Uwing with patient & $27(71.1 \%)$ & $7(58.4 \%)$ \\
Number of hours contact & & \\
per week & $8(21.1 \%)$ & $3(25.0 \%)$ \\
up to 19 hours & $9(23.7 \%)$ & $3(25.0 \%)$ \\
19 to 35 hours & $21(55.3 \%)$ & $6(50.0 \%)$ \\
more than 35 hours &
\end{tabular}

1. One relative was the partner of the patient, and was recorded as a missing value.
The overall score of burden for women primary carers was examined in relation to their characteristics lage, relationship to patient, employment status, whether living with partner, whether living with patient, and number of hours face-to-face contact with patient per week), and to characteristics of patients (sex, age, number of previous admissions, and length of illness). Most characteristics of carers and patients were not associated with levels of burden. Carers living with patients had higher scores of burden than those not living with patients $(t=2.03$, d.f. $=34.39$. $P=0.049$ ), and there was an association between increasing number of hours of contact between patients and carers and higher scores of burden $\left(F_{1.35}=7.18, P=0.01\right)$. Overall scores of burden were positively correlated with the carer's perception of patients' social role performance ( $r=0.63, P<0.001)$ and behavioural problems $(r=0.35, P=0.03)$, higher scores on SRP and SBS meaning worse social functioning.

\section{Comment}

Now that care in the community is an established fact. with the time that patients spend in hospital much reduced compared with former decades (e.g. Melzer et al, 1991), much of the burden of this care inevitably falls to relatives. It seems timely, therefore, to consider the particular needs of this group of carers, who continue to be described as having high levels of burden (Gibbons et al, 1984; MacCarthy et al, 1989; Tessler \& Gamache, 1994).

The sample in this study was composed of carers of patients who were in acute psychotic crisis, therefore they might be experiencing higher levels of burden than carers of patients who are stable in the community. In spite of that, our study confirms that women carers were in the majority, were likely to be living with the patient but not with a partner. Over half of them were also holding down a job outside the home. Not surprisingly, the impact of care was high in all areas asked about: relationships, household affairs, employment, finances and social life. These findings support the stereotype of an adult son with schizophrenia, living with a middleaged or elderly mother who is effectively a single parent. The only new finding in the 1990s appears to be that over half of these women also have an outside job.

In order to offer support for the caring role, which is often undertaken not only out of duty but also out of care and love, services need to consider how to help women carers, both in their multiple roles, and over long time periods.

There is evidence that relative groups, both formal or informal, help to provide direct emotional support and relieve isolation (Kuipers et al. 
1989). There is also good evidence that respite care is a need identified by relatives (MacCarthy et al, 1989), and might be particularly appreciated by women carers. Increasingly this is no longer provided by hospitals, but by nonstatutory providers, and is thus patchily available around the country. We know that planned respite is likely to reduce acute admissions and work preventatively to maintain community living arrangements by offering a break from the strain that these can entail. In the long term this means that respite is extremely costeffective.

Finally, even if respite and support groups were readily available on request, they both assume that women will continue to be the ones who can be relied upon to offer the caring role. However, the changing role of women in society, the fact that most will have multiple roles, and that many 'family' units are both small and isolated, suggests that these assumptions are already being challenged. Services need to be aware that relying on women to provide these high levels of care, even with support, will not necessarily be an option in the future. It is likely that we will need to plan for more flexible systems, such as a variety of highly supported housing, so that relatives can feel that they have choices and can maintain contact without always having to bear the whole impact of continuing care.

\section{Acknowledgement}

M. S. was funded by the CNPq-Brasilia, Brazil.

\section{References}

American Psychiatric Association (1987) Diagnostic and Statistical Manual of Mental Disorders (3rd edn. revised) (DSM-III-R). Washington, DC: APA.

Biegel, D. E., Milugan, S. E., Putnam, P. L., et al (1994) Predictors of burden among lower socioeconomic status caregivers of persons with chronic mental illness. Community Mental Health Journal, 30, 473-494.

BREWIN, C. R., Wing, J. K., MANGEN, S. P., et al (1987) Principles and practice of measuring needs in the longterm mentally ill: the MRC Needs for Care Assessment. Psychological Medicine, 17, 971-981.

-. Veltro, F., Wing, J. K., et al (1990) The assessment of psychiatric disability in the community. A comparison of clinical, staff, and family interviews. British Joumal of Psychiatry. 167, 671-674.

Carpentier, N., Lesage, A., Goulet, J., et al (1992) Burden of care of families not living with young schizophrenic relatives. Hospital and Community Psychiatry. 43. 38-43.
CREer, C. \& Wing, J. K. (1975) Living with a schizophrenic patient. British Journal of Hospital Medicine, 14, 73-82.

Deasy, L. S. \& QuinN, O. W. (1955) The wife of the mental patient and hospital psychiatrist. Joumal of Social Issues, 11, 49-60.

Gibbons, J. S., Horn, S. H., Poweu, J. M., et al (1984) Schizophrenic patients and their families: a survey in a psychiatric service based on a DGH unit. British Journal of Psychiatry. 144, 70-77.

GraD, J. \& SAINSBURY, P. (1968) The effects that patients have on their families in the community care and a control psychiatric service: a two year follow-up. British Journal of Psychiatry. 114, 265-278.

KuIPERS, L., MACCARTHY, B.. HURRY, J., et al (1989) Counselling the relatives of the long-term adult mentally ill. II. A low-cost supportive model. British Journal of Psychiatry. 164, 775-782.

MacCARTHY, B., LesAge, A., BREWIN, C. R. et al (1989) Needs for care among the relatives of long-term users of day care. Psychological Medicine, 19, 725-736.

Melzer, D., Hale, A. S., MaLK, S. J., et al (1991) Community care for patients with schizophrenia one year after hospital discharge. British Medical Journal, sos. 1023-1026.

PLATT, S. (1985) Measuring the burden of psychiatric illness on the family: an evaluation of some rating scales. Psychological Medicine, 15, 383-393.

-. Weyman, A., Hirsch, S., et al (1980) The Social Behavior Assessment Schedule (SBAS): rationale, contents, scoring and reliability of a new interview schedule. Social Psychiatry. 16. 43-55.

SCAZUFCA, M. \& KuIPERS, E. (1996) Links between expressed emotion and burden of care in relatives of patients with schizophrenia. British Journal of Psychiatry, 168. 580-587.

STEVENS, B. C. (1972) Dependence of schizophrenic patients on elderly relatives. Psychological Medicine, 2, 17-32.

Tessler, R. \& Gamache, G. (1994) Continuity of care, residence, and family burden in Ohio. Milbank Quarterly, 72. 149-169.

Thompson, E. H. \& Dol.. W. (1982) The burden of families coping with the mentally ill: an invisible crisis. Family Relations, 35, 379-389.

THURER, S. L. (1983) Deinstitutionalization and women: where the buck stops. Hospital and Community Psychiatry, 34, 1162-1163.

VAughn, C. E. \& LeFF, J. P. (1976) The measurement of expressed emotion in the families of psychiatric patients. British Journal of Social and Clinical Psychology, 15, 157-165.

Wrkes, T. \& STURT, E. (1986) The measurement of social behaviour in psychiatric patients: an assessment of the reliability and validity of the SBS schedule. British Journal of Psychiatry. 148, 1-11.

Marcia Scazufca, Clinical Psychologist, and *Elizabeth Kuipers, Reader in Clinical Psychology, Department of Psychology, Institute of Psychiatry, De Crespigny Park, London SE5 8AF

*Correspondence 